\title{
Um Produto Educacional em Educação Financeira Escolar
}

\section{Luciana Aparecida Borges Losano}

Docente da Escola Municipal Monsenhor Lopes, Barbacena/MG

lab10803@hotmail.com

\section{Resumo}

Neste artigo apresentamos e discutimos o Produto Educacional desenvolvido junto ao Programa de Mestrado em Educação Matemática da Universidade Federal de Juiz de Fora. O objetivo desse trabalho foi elaborar tarefas de Educação Financeira que estimulassem a produção de significados diante dos conceitos tratados em cada situação-problema e analisá-las sob a ótica do Modelo dos Campos Semânticos. O conjunto de tarefas foi apresentado a duas duplas de alunos do $6^{\circ}$ ano do Ensino Fundamental. Num segundo momento, as tarefas foram apresentadas a uma sala de aula de $6^{\circ}$ ano do Ensino Fundamental.

Palavras-chave: Educação Matemática. Produto Educacional. Educação Financeira Escolar. Produção de Significados. Mestrado Profissional.

\section{An Education Product in School Financial Education}

\begin{abstract}
In this article we present and discuss the educational product developed by the Master's Program in Mathematics Education, Federal University of Juiz de Fora. The aim of this study was to develop financial education tasks that stimulate the production of meanings on the concepts discussed in each problem situation and analyze them from the perspective of Model of Semantic Fields. The set of tasks was presented to two pairs of students of the 6th year of elementary school. Secondly, the tasks were brought to a classroom of 6th year of elementary school.
\end{abstract}

Keywords: Mathematics Education. Education Product. School Financial Education. Meanings of production. Professional Masters.

\section{Introdução}

No presente artigo apresentaremos o processo de produção de um produto educacional para o ensino de Educação Financeira em aulas de matemática do Ensino fundamental.

Este produto foi desenvolvido junto ao Programa de Pós-Graduação em Educação Matemática, da Universidade Federal de Juiz de Fora, na modalidade de mestrado profissional. Nessa modalidade, o produto educacional deve ser parte integrante do trabalho final de Curso 
elaborado conjuntamente com a dissertação, como se observa no documento de área da Capes ${ }^{1}$ (2009):

A dissertação do mestrado profissional em ensino deve, necessariamente, apresentar um
produto educacional que possa ser disseminado, analisado e utilizado por outros
professores. Este produto, que deve ser destacável do corpo da dissertação, pode ter a forma
de um texto sobre uma seqüência didática, um aplicativo computacional, um vídeo (na
internet ou em CD/DVD), um equipamento; enfim, algo identificável e independente da
dissertação. (CAPES, 2009)

Como se pode observar no documento de área, os mestrados profissionais na Área de Ensino e em outras áreas de conhecimento surgiram com objetivo diferente dos mestrados acadêmicos em que o foco está na aplicação do conhecimento, ou seja, na pesquisa aplicada e no desenvolvimento de produtos e processos educacionais que sejam utilizáveis em condições reais de ensino. Na direção desta orientação, existe a obrigatoriedade da apresentação de um produto educacional passível de análise e utilização por outros profissionais. O objetivo deste artigo é exatamente este, discutir e também divulgar um produto educacional que aborda uma perspectiva de inserção da Educação Financeira na Educação Básica.

O produto educacional que apresentaremos a seguir integra a dissertação de Mestrado Profissional intitulada "Design de tarefas de Educação Financeira para o $6^{\circ}$ ano do Ensino Fundamental" (LOSANO, 2013). Nesta investigação, de caráter qualitativo, buscamos desenvolver tarefas sobre Educação Financeira que pudessem ser utilizadas em salas de aula de Matemática do $6^{\circ}$ ano do Ensino Fundamental. Elas foram aplicadas em uma escola da rede municipal de Minas Gerais e os dados obtidos analisados. Todo o processo, desde a concepção das tarefas, passando pela aplicação e análise dos significados produzidos pelos estudantes foi referenciada teoricamente pelo Modelo dos Campos Semânticos proposto por Lins (1999, 2012).

O objetivo da investigação foi elaborar tarefas de Educação Financeira que estimulassem a produção de significados dos estudantes em sala de aula diante dos conceitos tratados em cada situação-problema e analisá-las sob a ótica do Modelo dos Campos Semânticos. O conjunto de tarefas, após a pesquisa de campo veio a se constituir no produto educacional como descreveremos em detalhes a seguir.

\section{Uma proposta de Educação Financeira Escolar}

Nosso projeto de pesquisa que gerou o produto educacional em discussão é parte de um projeto maior intitulado Design e Desenvolvimento de um Programa de Educação Financeira para a formação de Estudantes e Professores da Educação Básica, em que uma de suas frentes é a produção de material didático para a sala de aula.

\footnotetext{
${ }^{1}$ Coordenação de Aperfeiçoamento de Pessoal de Nível Superior
} 
Várias pesquisas foram desenvolvidas nesse projeto tendo o Modelo dos Campos Semânticos como referencial teórico e as concepções de Silva e Powell (2013) como orientadoras da pesquisa. (Cf. CAMPOS, 2012; SANTOS, 2014; GRAVINA, 2014; VITAL, 2014; DIAS, 2015)

A nossa pesquisa foi inserida nesse projeto considerando que nossa perspectiva como professora e pesquisadora visa contribuir para a formação do aluno cidadão, consciente de seus deveres e direitos, com conhecimentos necessários para auxiliá-los na tomada de decisões financeiras. Nessa direção, a perspectiva de Educação Financeira, apresentada por Silva e Powell (2013) nos interessou por ter esta finalidade. Ela pretende formar estudantes da Educação Básica de escolas públicas em Educação Financeira, como parte de sua educação matemática, baseada na análise de situações problemas auxiliares na tomada de decisões financeiras.

Assim, em nossa pesquisa, as concepções propostas por esses pesquisadores orientaram toda a investigação. Por exemplo, assumimos a caracterização para a Educação Financeira Escolar proposta, nos seguintes termos:

A Educação Financeira Escolar constitui-se de um conjunto de informações através do qual os estudantes são introduzidos no universo do dinheiro e estimulados a produzir uma compreensão sobre finanças e economia, através de um processo de ensino que os torne aptos a analisar, fazer julgamentos fundamentados, tomar decisões e ter posições críticas sobre questões financeiras que envolvam sua vida pessoal, familiar e da sociedade em que vivem (SILVA e POWELL, 2013, p.12).

Com o objetivo geral de desenvolver o pensamento financeiro nos estudantes Silva (2013) elaborou cinco objetivos específicos. São eles:

$>$ compreender as noções básicas de finanças e economia para que desenvolvam uma leitura crítica das informações financeiras presentes na sociedade;

$>$ aprender a utilizar os conhecimentos de matemática (escolar e financeira) para fundamentar a tomada de decisões em questões financeiras;

$>$ desenvolver um pensamento analítico sobre questões financeiras, isto é, um pensamento que permita avaliar oportunidades, riscos e as armadilhas em questões financeiras;

$>$ desenvolver uma metodologia de planejamento, administração e investimento de suas finanças através da tomada de decisões fundamentadas matematicamente em sua vida pessoal e no auxílio ao seu núcleo familiar;

$>$ analisar criticamente os temas atuais da sociedade de consumo (SILVA e Powell, 2013, p. 13).

Estes objetivos nortearam o desenvolvimento de uma estrutura curricular em três dimensões: a dimensão pessoal, a familiar e a social.

A proposta é organizar o currículo a partir de quatro eixos norteadores: noções básicas de finanças e economia; finança pessoal e familiar; as oportunidades, os riscos e as armadilhas na gestão do dinheiro numa sociedade de consumo; as dimensões sociais, econômicas, políticas, culturais e psicológicas que envolvem a Educação financeira (SILVA e POWELL, 2013).

De acordo com esses eixos norteadores um material didático baseado na produção de tarefas vem sendo desenvolvido. A primeira pesquisa nessa direção foi a de Campos (2012). Na sequência, foi desenvolvida a nossa pesquisa e novos estudos estão em andamento ou concluídos. 
As investigações visam à construção de um currículo que tem como princípio organizador os modos de produção de significados (no sentido proposto por Lins, 1999, 2013). Assim discutiremos a seguir os principais elementos constitutivos deste modelo epistemológico.

\section{A Revisão Teórica}

A pesquisa que resultou na elaboração do Produto Educacional foi orientada pelo Modelo dos Campos Semânticos (MCS) proposto por Rômulo Campos Lins (LINS, 1999, 2012).

A escolha dessa teoria se baseia na possibilidade de, a partir dela, entendermos a diversidade de produções de significado de nossos sujeitos de pesquisa ou de nossos estudantes nos processos de ensino e aprendizagem em sala de aula.

As noções que utilizamos mais diretamente em nossa pesquisa são as noções significado, produção de significados, processo comunicativo e as chamadas noções categorias que nos permitem analisar a fala de nossos sujeitos de pesquisa. Obviamente assumimos todos os pressupostos do MCS, mas apresentaremos aqueles que são necessários para esclarecer a elaboração das tarefas.

A noção de significado de um objeto, neste artigo, será entendida como aquilo que o sujeito pode e efetivamente diz sobre um objeto no interior de uma atividade. (LINS, 1999)

Como consequência, dizer que um sujeito produziu significados é dizer que ele produziu ações enunciativas a respeito de um objeto no interior de uma atividade. (SILVA, 2003)

Além disso, produzir significados não se refere a tudo o que numa dada situação o sujeito poderia ou deveria dizer de um objeto e sim o que ele efetivamente diz sobre aquele objeto no interior daquela atividade. (LINS \& GIMENES, 1997, p.145). Assim, os objetos são constituídos enquanto tal através do que o sujeito diz que eles são.

Em sua elaboração do MCS, Lins apresentou uma nova perspectiva para o processo comunicativo, constituído pela tríade autor-texto-leitor, motivado pela seguinte questão: “É possível comunicação, no sentido, por exemplo, da transmissão de uma mensagem de uma pessoa para outra?" (LINS, 1999).

Para ele, segundo o senso comum, a comunicação efetivamente acontece porque as mensagens emitidas referem-se a um mundo que é objetivo. Porém, para o francês Jacques Derrida, a comunicação é um acidente, a norma é a não comunicação. (LINS, 1999, p.81)

Ele então propõe uma visão alternativa constituída pela tríade autor-texto-leitor. Ele explica que quando "um autor" fala, ele fala para "um leitor". Porém, "um leitor" só o será caso o texto que "o autor" enunciou produza significados para "o leitor". O texto só é texto caso "o leitor" 
produza significados para o que ele denominou resíduo de enunciação. Portanto, texto e leitor só serão assim constituídos se houver produção de significados.

É importante destacar que, para Lins, os 'um autor' e 'um leitor' são seres cognitivos e não, necessariamente biológicos, que são genericamente chamados de interlocutor. Em suas palavras:

Quem produz uma enunciação é o autor. O autor fala sempre na direção de um leitor, que é constituído (produzido, instaurado, instalado, introduzido) pelo o autor. Quem produz significado para um resíduo de enunciação é o leitor. O leitor sempre fala na direção de um autor, que é constituído (produzido, instaurado, instalado, introduzido) pelo o leitor. (LINS, 2012, p.14)

A noção de comunicação, de acordo com nossos interesses, sugere que quando um professor apresenta aos seus alunos uma situação problema, esta é entendida como um resíduo de enunciação, e somente se constituirá em texto a partir do momento que o leitor, que em nosso estudo caso são os alunos, produzirem significados para este resíduo. Assim, no processo de ensino o professor deverá ler o que seus alunos estão dizendo, se constituindo em leitor de suas enunciações.

Segundo Silva (2003), as noções categorias do MCS determinam o que o pesquisador deve considerar em sua análise. Nessa direção, ele observa:

(...) quando uma pessoa se propõe a produzir significados para o resíduo de uma
enunciação, observamos da perspectiva do MCS o desencadeamento de um processo
(mencionado na introdução) - o processo de produção de significados - que envolve: i) a
constituição de objetos - coisas sobre as quais sabemos dizer algo e dizemos - que nos
permite observar tanto os novos objetos que estão sendo constituídos quanto os significados
produzidos para esses objetos; ii) a formação de um núcleo: o processo que envolve as
estipulações locais, as operaçães e sua lógica; iii); a fala na direção de interlocutores; e, iv)
as legitimidades, isto é, o que é legítimo ou não dizer no interior de uma atividade. (SILVA,
2003, p.66)

São esses os elementos teóricos que levamos para a elaboração das tarefas e posterior análise da produção de significados dos estudantes na pesquisa de campo.

\section{Metodologia de Elaboração do Produto Educacional}

O produto educacional que desenvolvemos caracteriza-se, conforme designação no documento da Área de Ensino (Capes, 2013), como uma sequência didática, constituída por um conjunto de tarefas para uso em sala de aula de matemática. (Cf. CAPES, 2013, p.53)

O universo de pesquisa foi uma sala de aula do $6^{\text {a }}$ ano do Ensino Fundamental de uma escola municipal de um distrito de Barbacena/MG (Senhora das Dores), na qual atuamos há 16 anos. Na aplicação das tarefas em sala de aula, os alunos trabalharam em trios. Dessa forma, puderam conversar e negociar suas produções de significado. Eles receberam folhas com as tarefas impressas e pedimos para que refletissem a respeito dos objetos tratados. 
O processo de elaboração das tarefas foi orientado por três objetivos principais. Primeiro, as tarefas foram construídas com base na proposta de um currículo de Educação Financeira formulada por Silva e Powell (2013) e na concepção do MCS. Assim, as tarefas tinham como propósito estimular a produção de significados dos alunos e ampliar as possibilidades de estratégias de resolução ao invés de reduzí-las a uma única solução. Além disso, elas seriam direcionadas a possibilitar que vários elementos do pensar matematicamente estivessem em discussão, como a análise da razoabilidade dos resultados e o desenvolvimento de estratégias próprias de resolução de problemas.

O segundo objetivo estava voltado para auxiliar o professor em sala de aula, de modo a lhe permitir: (a) observar os diversos significados sendo produzidos pelos alunos e incentivar que esses significados se tornassem objeto de atenção deles; (b) deixar claro que os significados produzidos por eles e/ou os significados oficiais da matemática são alguns entre os vários significados que podem ser produzidos a partir de uma tarefa; (c) tratar do que é matemático, junto com os significados não matemáticos que possivelmente estejam presentes naquele espaço comunicativo. Esta perspectiva esteve orientada pelas concepções presentes em (LINS; GIMENEZ, 1997).

O terceiro objetivo foi listar as características que deveriam ser levadas em consideração ao confeccionar as tarefas. As características listadas foram: (i) as tarefas deveriam ser projetadas para uso em salas de aulas de matemática; (ii) as tarefas deveriam ser abertas; isto é, permitir diferentes caminhos de resolução e de resposta dos alunos (iii) as tarefas deveriam ser elaboradas a partir de contextos que permitissem aos alunos aprender sobre temas de Educação Financeira produzindo significados matemáticos e não-matemáticos.

Para a análise das potencialidades das tarefas foi programada uma pesquisa de campo em dois momentos. No primeiro momento as tarefas seriam aplicadas a duas duplas de alunos do $6^{\circ}$ ano e; no segundo momento, as tarefas seriam aplicadas em uma turma de alunos também do mesmo ano, utilizando na análise as noções categorias do MCS. O que descrevermos a seguir apresenta as duas fases da pesquisa: a concepção da tarefa e alguns resultados da pesquisa de campo.

Assim, antes da saída a campo e após a definição dos objetivos o passo seguinte consistiu em considerar que tarefas seriam pertinentes para iniciar com os estudantes uma discussão sobre o universo do dinheiro.

Nossa opção metodológica foi por elaborar um conjunto de tarefas que discutisse, inicialmente, os seguintes temas: o que é dinheiro? Para que serve? Como consegui-lo? Isto nos permitiria desenvolver uma avaliação diagnóstica do que os estudantes sabiam sobre o dinheiro. Esta opção gerou a seguinte tarefa: 
Fernanda é uma menina de 10 anos e outro dia ela sonhou que estava num planeta distante e encontrou um extraterrestre. Fernanda queria mostrar ao ET alguma coisa da Terra e a única coisa que ela havia levado em seu bolso era uma nota de R\$10,00. Ela mostrou ao ET e disse que era dinheiro, que seu pai tinha dado a ela. O ET então perguntou

- O que é dinheiro?

- Para que as pessoas usam dinheiro no seu mundo?

- Como os seus pais conseguem dinheiro?

Ao acordar, Fernanda ficou pensando nas melhores respostas que ela poderia dar ao ET. Quais respostas você daria para as perguntas feitas pelo ET?

Fonte: Losano (2013)

Em nossa pesquisa, observamos que os alunos precisaram de uma aula de cinquenta minutos para desenvolver esta primeira tarefa. Eles conversaram, discutiram e buscaram apresentar respostas aos questionamentos.

Esta tarefa, além de contribuir para que o professor faça uma leitura sobre os significados que os alunos produzem para o dinheiro, formas de obtenção e utilização, possibilita uma introdução sobre a discussão de finanças no $6^{\circ}$ ano.

A respeito das produções de significado para o primeiro questionamento, notamos que a maior parte dos alunos teve a preocupação de apontar características das cédulas. Assim, alguns disseram que "dinheiro é uma folha de papel, colorida, com animais, com números". Outros lembraram que "o dinheiro vale muito no nosso mundo, que usamos [o dinheiro] para comprar as coisas: roupas, remédios, comida, material escolar, para pagar as dívidas". No último questionamento, eles afirmaram que "nossos pais conseguem trabalhando". Dessa forma, associaram a obtenção do dinheiro ao trabalho.

A tarefa 2 foi intitulada $A$ mesada e teve como objetivo discutir com os estudantes questões ligadas a orçamento pessoal, planejamento e uso do dinheiro. O objetivo da tarefa foi estimular o processo de produção de significados para questões de orçamento pessoal, como corte de despesas, análise dos gastos e tomada de decisão no uso do dinheiro. Os personagens apresentados eram adolescentes que ganhavam o dinheiro por ajudar o pai na loja da família e os gastos eram próprios da idade.

A matemática envolvida, em geral, foi adições, subtrações e multiplicações com números naturais ou decimais; relação entre semana/mês. 
Fernanda continuou pensando durante o dia sobre o uso do dinheiro e ao encontrar seus amigos Bruno e Giovanna, que são irmãos, eles estavam falando justamente sobre dinheiro. Contaram à Fernanda que ajudam seu pai na loja da família e, que por esta ajuda seu pai resolveu dar uma mesada em dinheiro no valor de $\mathrm{R} \$ 150,00$ a cada um. Porém, eles devem planejar como gastá-la, pois nenhum outro dinheiro será dado ao longo do mês e eles deverão cuidar de seus próprios gastos.

Assim eles resolveram programar o uso do dinheiro. Giovanna sugeriu a Bruno que fizessem os cálculos de quanto gastavam por semana. O resultado você pode ver abaixo:

$\begin{array}{lc}\text { Giovanna: } & 2,00 \times 5=10,00 \\ \text { Compras na cantina da escola }\left(2^{\mathrm{a}} \text { a } 6^{\mathrm{a}} \text { feira }\right) & 4,40 \times 5=22,00 \\ \left.\text { Ônibus para a escola ( } 2^{\mathrm{a}} \text { a } 6^{\mathrm{a}} \text { feira }\right) \text { ida e volta } & 15,00 \\ \text { Saída aos sábados com as amigas } & 15,00 \\ \text { Algumas compras na semana } & 10,00\end{array}$

Bruno:

Compras na cantina da escola $\left(2^{\mathrm{a}}\right.$ a $6^{\mathrm{a}}$ feira $)$ $3,00 \times 5=15,00$

Ônibus para a escola ( $2^{\mathrm{a}}$ a $6^{\mathrm{a}}$ feira) ida e volta $4,40 \times 5=22,00$

Balas e doces ( 3 vezes por semana) $2,00 \times 3=6,00$

Saída aos sábados com a turma 10,00

Aluguel de videogame 8,00

Ao olhar as contas, Fernanda ficou pensando nas seguintes questões que sugerimos que você também pense e responda para entender o que está se passando, financeiramente, com Bruno e Giovanna.

a) O dinheiro que Giovanna e Bruno receberão de mesada será suficiente para seus gastos durante o mês, considerando que todas as semanas eles gastam a mesma quantia?

b) Que corte nos gastos semanais você sugere que deveria ser feito para eles gastarem apenas o que ganham de mesada? Faça as contas.

c) Quantos reais os irmãos economizariam se na ida e na volta da escola eles fossem a pé com a mãe de seu amigo, que mora na casa ao lado da sua?

(Adaptado de Campos, 2012, p.86)

Fonte: Losano (2013) 
Nesta tarefa, utilizamos duas aulas de cinquenta minutos. Na primeira, os alunos fizeram seus cálculos e, na outra, discutiram as ideias surgidas no desenvolvimento.

O orçamento foi propositalmente colocado acima do valor da mesada, que era de $\mathrm{R} \$ 150,00$. No item $\mathrm{b}$, solicitamos aos alunos que fizessem cortes no orçamento a fim de que os gastos fossem iguais ou menores a esse valor. Isto contribuiu para que eles pudessem analisar e rever os gastos apresentados além de proporcionar uma diversidade de tomadas de decisões.

Outra questão instigante é a diferença temporal. As despesas foram colocadas semanalmente, enquanto o valor recebido era mensal. Isso provocou questionamentos sobre a quantidade de semanas que há em um mês. Tal fato nos levou a devolver indagações: Quantos dias têm uma semana? Quantos dias têm um mês? Quantas vezes o sete cabe em trinta?

Discussões de âmbitos variados emergiram como o corte do ônibus ou as consequências de ir à pé para a escola. O item "Balas e doces" com previsão de gastos três vezes por semana gerou produções de significados no tocante a atitudes alimentares saudáveis. Os alunos discutiram questões relativas à saúde bucal e à obesidade infantil. O aluguel de videogame proporcionou debates quanto à compra ou não de jogos piratas.

Portanto, muito além dos significados matemáticos, pretendemos, com nossa proposta, favorecer o desenvolvimento de questões reflexivas, que instigue cada aluno a repensar seus pequenos gastos e suas atitudes, tendo ou não o benefício da mesada. Isso reforça nossa premissa, que é a educação através da Matemática.

Na Tarefa 3, denominada Fazendo o próprio orçamento, o objetivo foi estimulá-los a elaborar o próprio orçamento e como consequência, levá-los a olhar para os próprios gastos. Esta tarefa é uma continuação das discussões da tarefa anterior sobre orçamento pessoal que pretendia trazer a reflexão dos estudantes temas como consumismo, necessidade e desejo.

A matemática envolvida na atividade era, em geral, adições, subtrações e multiplicações com números naturais ou decimais.

\section{Quadro 3 - Fazendo o próprio orçamento}

Fernanda, inspirada em Bruno e Giovanna, resolveu fazer os cálculos de quanto gostaria de gastar durante a semana. Com isso, ela percebeu que poderia fazer uma proposta de mesada aos seus pais. Faça você também suas contas! Anote as coisas que você costuma gastar durante a semana.

Fonte: Losano (2013)

Nessa tarefa, utilizamos uma aula de 50 minutos. No primeiro momento, os alunos elaboraram seus orçamentos semanais e mensais, fazendo os cálculos. Num segundo momento, abrimos uma roda de discussão para que os orçamentos fossem discutidos, permitindo aos alunos 
que lessem, criticassem, refletissem, ponderassem sobre seus gastos. Vale observar que diversos temas puderam ser abordados tais como a dualidade necessidade $\mathrm{x}$ desejo, o que é barato, o que é caro, a possibilidade ou razoabilidade de pedir uma mesada.

Assim como um adulto que tem seu salário e precisa planejar como vai gastá-lo, as crianças podem compreender o universo das finanças e economia começando a planejar como devem gastar o dinheiro que recebem de mesada.

Observamos durante a aplicação desta tarefa, e também em outros momentos, os diferentes perfis de consumo das crianças. Enquanto, os alunos identificados pelos pseudônimos Pilar e Artur sinalizam um perfil mais esbanjador, Cássia e Júnior parecem ser mais comedidos e prudentes nos gastos. Tais observações contribuem para questionarmos a possível influência que as atitudes dos pais podem determinar em seus filhos ou mesmo a situação financeira pela qual passam as famílias.

Outro fato marcante foi à questão do desejo de consumo, que levou alguns sujeitos de pesquisa a falarem sobre gastos fictícios. Isto deu margem para discutirmos novamente sobre necessidade e desejo.

A Tarefa 4 denominada Orçamento familiar, teve como objetivo discutir com os estudantes temas ligados ao orçamento, tais como, as noções de receitas e despesas, despesas extras, reserva orçamentária, orçamento familiar, salário e dívidas. Conforme discutimos anteriormente, o currículo proposto em Silva (2013) não abrange apenas a dimensão pessoal, mas também a social e familiar.

A matemática envolvida na resolução da tarefa foi, em geral, adições e subtrações com números naturais e/ou decimais.

\section{Quadro 4 - Orçamento Familiar}

Fernanda, ao voltar para casa, resolveu perguntar ao seu pai como e para que ele usava o dinheiro. Seu pai convidou-lhe para conversar sobre orçamento familiar. Acompanhe a conversa entre os dois.

Pai: Nossa família é formada por mim, você, sua mãe e seu irmão Álvaro. E uma família tem que ter dinheiro para atender as suas necessidades. Por causa disso, eu trabalho em uma empresa e recebo um dinheiro todo mês pelo que faço, chamado salário. Sua mãe não possui um emprego fixo, então ela não possui salário e por isso ela recebe um mês mais dinheiro, outro mês menos dinheiro. Quando juntamos o dinheiro que ganhamos, usamos para cuidar da nossa casa e de vocês.

Fernanda: Mas o que é orçamento familiar?

Pai: Ah, então! O orçamento familiar é o controle que devemos fazer para não gastar mais dinheiro do que ganhamos. Para isso, precisamos conhecer nossos gastos (as despesas) e quanto ganhamos de dinheiro (a receita).

Fernanda: Mas, por quê?

Pai: Uma família tem muitos gastos, mas o que a gente gasta não pode ser mais do que a gente ganha, 
senão a gente passa a ter dívidas. E isto não é bom.

Fernanda: O que é dívida?

Pai: É quando uma pessoa gasta mais do que tem de dinheiro. Por exemplo, todo mês temos que pensar em como equilibrar o orçamento. Vou lhe mostrar nosso orçamento do mês de abril para que você tome algumas decisões.

Mês: Abril

Receitas

\begin{tabular}{c|c} 
Salário (Pai) & 589,86 \\
\hline Renda (mãe) & 550,00 \\
\hline Total &
\end{tabular}

\begin{tabular}{l|r}
\multicolumn{1}{c|}{ Despesas } & \multicolumn{1}{c}{ Valor } \\
\hline Aluguel & 300,00 \\
\hline Água & 30,00 \\
\hline Luz & 70,00 \\
\hline Supermercado & 200,00 \\
\hline Padaria & 80,00 \\
\hline Telefone (fixo) & 60,00 \\
\hline Telefone (celular) & 50,00 \\
\hline Açougue & 50,00 \\
\hline Transporte & 40,00 \\
\hline Farmácia & 50,00 \\
\hline Prestação (última parcela) & 100,00 \\
\hline Total de despesas & \\
\hline Receitas & \\
\hline Total & \\
\hline &
\end{tabular}

Fernanda, pergunto a você:

1) Antes de fazer as contas, comente o que acontecerá se:

a) O valor da receita for igual ao valor das despesas?

b) O valor da receita for maior do que o valor das despesas?

c) O valor da receita for menor do que o valor das despesas?

2) Faça as contas do total da receita e das despesas e veja o que está acontecendo no orçamento de abril. 


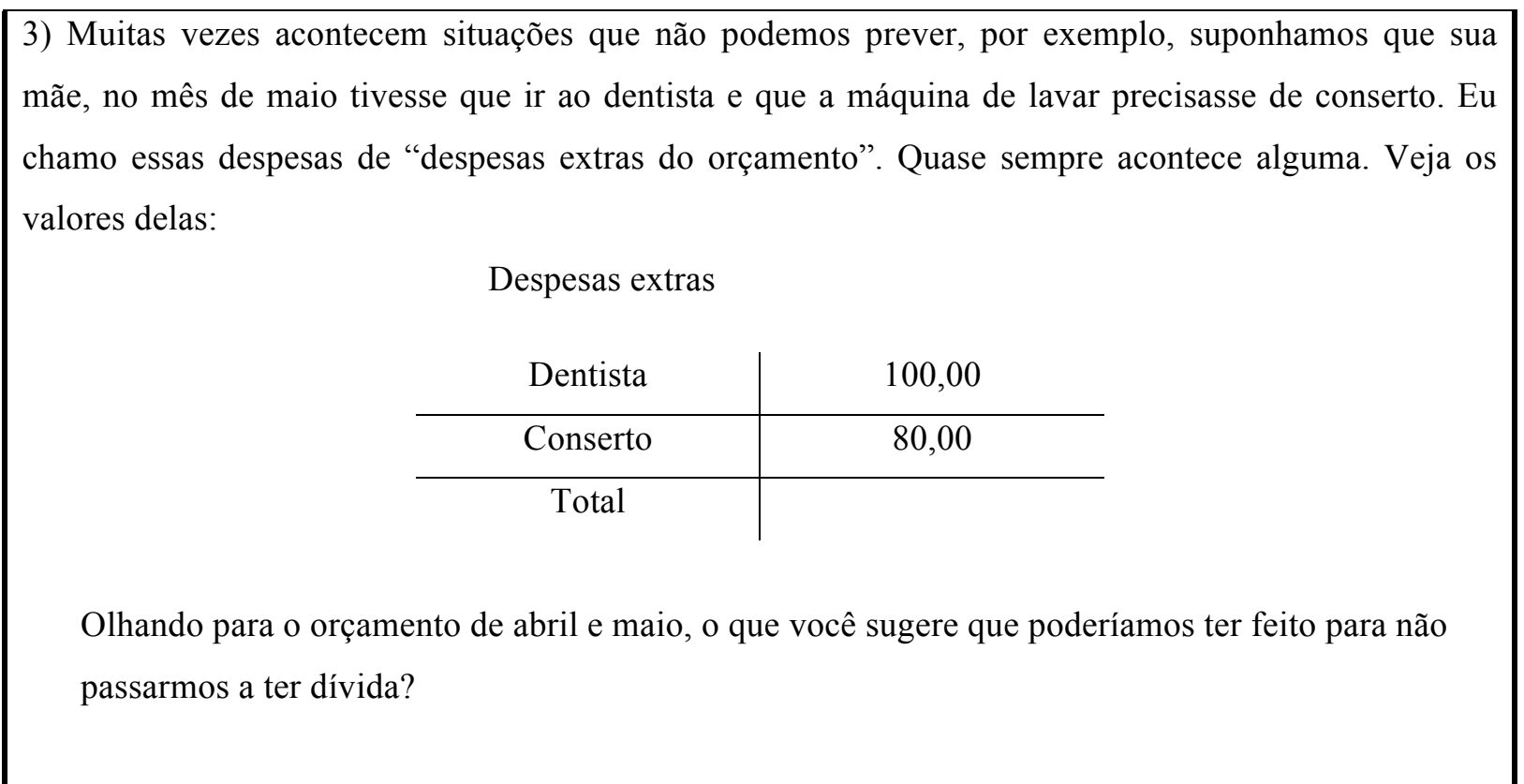

Fonte: Losano (2013)

Nesta tarefa, utilizamos duas aulas, uma para que os alunos desenvolvessem os cálculos e outra para a discussão em grupo.

Aproveitamos esse momento para indagar aos sujeitos de pesquisa como suas famílias fazem o orçamento familiar e quem administra os pagamentos. A aluna Cássia, que tem os pais separados, relata que já viu o pai e a madrasta fazendo o orçamento da casa. Pilar conta que o pai o faz enquanto Artur diz que esta tarefa é desempenhada por sua mãe. Júnior diz que não sabe quem faz o orçamento.

Alguns questionamentos quanto aos valores apresentados no orçamento da família da Fernanda foram feitos pelas crianças. Pilar acha o valor do supermercado muito baixo, enquanto Júnior reclama da conta da Padaria, que é de R\$ 80,00. Artur não concordou com os dois telefones da família. Para ele, é legítimo que só haja um telefone e Júnior parece compartilhar interlocutores com Artur. Alguns alunos lembraram a importância de uma reserva para os momentos de emergência e também de que as dívidas sejam evitadas.

$\mathrm{O}$ que constatamos na pesquisa de campo foi que o conjunto de tarefas atendeu ao principal objetivo para o qual elas foram construídas: estimular a produção de significados dos alunos e de sugerir novos modos de produção de significados sobre temas ligados a Educação Financeira.

\section{Considerações finais}

Neste artigo discorremos acerca do Produto Educacional que foi fruto de nossa investigação de mestrado. A pesquisa que desenvolvemos contribuirá na discussão com nossos pares que atuam na 
educação básica, não apenas a relevância da Educação Financeira no contexto atual, mas também a necessidade de desenvolvermos uma leitura crítica sobre as propostas que podem surgir em nossas escolas.

Diante de um design de currículo proposto por Silva e Powell (2013), desenvolvemos um conjunto de quatro tarefas que foi aplicado em uma sala de aula do $6^{\circ}$ ano do ensino fundamental. Elas constituem um material passível de utilização e auxílio para que professores possam adaptá-las para desenvolver seu próprio material.

Vale ressaltar que estas tarefas não devem ser usadas como exercícios de fixação, nos quais o professor espera o aluno fazer e depois resolve no quadro apresentando respostas prontas. É importante deixar que os alunos falem, discutam suas ideias, proponham novas situações. Como professores, não devemos nos fixar no certo ou errado a partir do que o aluno diz, pois cada produção de significado deve ser ouvida sem que sejam feitos juízos de valor.

Em resumo, em nossa pesquisa, focamos, na elaboração de tarefas que estimulassem a diversidade de produções de significados dos estudantes em sala de aula, perspectiva que enriquece profundamente os processos de ensino e aprendizagem da Matemática. A Educação Financeira tem se mostrado um tema importante para a formação dos estudantes da Educação Básica e acreditamos que os alunos serão mais estimulados a estudá-la quanto mais compreenderem a sua importância em suas vidas.

\section{Referências}

BOGDAN, Roberto C.; BIKLEN, Sari Knopp. Investigação Qualitativa em Educação. Porto, Portugal. Porto Editora, 1994.

CAPES. Documento de Área - 2009 - Ensino de Ciências e Matemática. Brasília: Coordenação de Aperfeiçoamento de Pessoal de Nível Superior - Capes. Diretoria de Avaliação, 2009.

CAPES. Documento de Área - 2013 - Ensino de Ciências e Matemática. Brasília: Coordenação de Aperfeiçoamento de Pessoal de Nível Superior - Capes. Diretoria de Avaliação, 2013.

CAMPOS, M. B. Uma investigação sobre a Educação Financeira na Matemática do Ensino Fundamental. Dissertação (Mestrado Profisssional em Educação Matemática). Universidade Federal de Juiz de Fora, 2012.

DIAS, J. N. Educação Financeira Escolar: a noção de juros. 180 f. Dissertação (Mestrado Profissional em Educação Matemática). Universidade Federal de Juiz de Fora, Minas Gerais, 2015.

GRAVINA, R. C. Educação financeira escolar: orçamento doméstico. 130 f. Dissertação (Mestrado Profissional em Educação Matemática). Universidade Federal de Juiz de Fora, Minas Gerais, 2014.

LINS, Romulo Campos; GIMENEZ, Joaquim. Perspectivas em Aritmética e Álgebra para o

Século XXI. Campinas, Brasil: Papirus, 1997. 
LINS, Romulo Campos. Por que discutir teoria do conhecimento é relevante para a Educação Matemática. In: Bicudo, M. A. V. (Org.) Pesquisa em Educação Matemática: concepções e perspectivas. São Paulo: Editora UNESP, p. 75-94, 1999.

LINS, R. C. O Modelo dos Campos Semânticos: Estabelecimentos e notas de teorizações. In: Angelo, C. L. et al. (orgs.). Modelo dos campos semânticos e educação matemática: 20 anos de história, p. 11-30. São Paulo: Midiograf, 2012.

LOSANO, L.A.B. Design de tarefas de Educação financeira para o $6^{\circ}$ ano do ensino fundamental. 121 f. Dissertação (Mestrado Profissional em Educação Matemática). Universidade Federal de Juiz de Fora, Minas Gerais, 2013.

LOSANO, L. A. B. Tarefas de Educação Financeira para o $6^{\circ}$ ano do Ensino Fundamental. Produto Educacional. 27 f. (Mestrado Profissional em Educação Matemática). Universidade Federal de Juiz de Fora, Minas Gerais, 2013.

SILVA, Amarildo Melchiades da. Sobre a dinâmica da produção de significados para a matemática. 243 f. Tese (Doutorado em Educação Matemática). Universidade Estadual Paulista, Rio Claro, 2003.

SILVA, Amarildo Melchiades da. Uma experiência de Design em Educação Matemática: O Projeto de Educação Financeira Escolar. Projeto de Pesquisa (Estágio Pós-Doutoral) - Rutgers/New Jersey/EUA, Newark, 2011.

SILVA, Amarildo Melchiades da. POWELL, Arthur Belford. Um Programa de Educação Financeira para a Matemática Escolar da Educação Básica. Anais do XI ENEM - XI Encontro Nacional de Educação Matemática, Curitiba, 2013.

VITAL, M. C. Educação Financeira e Educação Matemática: Inflação de Preços. 199 f. Dissertação (Mestrado Profissional em Educação Matemática). Universidade Federal de Juiz de Fora, Minas Gerais, 2014. 